\title{
Enhancing Students' Creativity in Physics Classroom using Virtual Laboratory
}

Gunawan

Physics Education Study Program

Universitas Mataram

Mataram, Indonesia

gunawan@unram.ac.id
Nina Nisrina

\author{
Physics Education Study Program \\ Universitas Mataram \\ Mataram, Indonesia \\ ninanisrina77@gmail.com
}

Lovy Herayanti

Physics Education Study Program

IKIP Mataram

Mataram, Indonesia

lovyherayanti@ikipmataram.ac.id
Ni Made Yeni Suranti

Physics Education Study Program

Universitas Mataram

Mataram, Indonesia

surantiyeni@gmail.com

\begin{abstract}
The virtual laboratory can be used to support an experiment of physics for visualizing abstract concepts. This article discusses the effects of virtual laboratory towards improvement on student's creativity in three different schools. Creativity measured in this study included verbal, numerical, and figural. The research was conducted using a quasiexperimental method within the use of pretest and posttest control group design. The results showed differences regarding improvement in students' creativity in each school. In general, in all schools, experimental groups performed a higher level of improvement than control groups. Increase on each type of creativity in three schools were varied. All schools demonstrated that verbal type was higher than numerical and figural ones. It was also revealed that level of increase, of three schools, were on a medium level. This research suggested that the use of virtual laboratory could improve students' creativity.
\end{abstract}

Keywords - Students' creativity; virtual laboratory; physics classroom

\section{INTRODUCTION}

The paradigm of education in Indonesia is changing along with the shift of civilization. It is marked by a high demand for students to develop their high order thinking skills, in which creativity is one among others. Therefore, the learning process, as a component of education, is expected to give motivation to students to be creative. Teachers as facilitators should also well prepared in selecting and using sophisticating learning media, which may facilitate teachers in delivering course materials and students in comprehending the course sophisticatedly [1].

Physics, as one element in science, is playing a significant role in the process of producing students with high-quality achievement. Learning physics is dealing with acquisition of comprehension on various fundamental concepts to enable someone to know when, how, and why physics can be applied [2]. On the other hand, some concepts in physics identified as abstract seem to be problems for teachers in delivering and visualizing it to students. As a consequence, students fail to achieve an optimal understanding of particular concepts. Moreover, this influences students' creative thinking skill in solving physic problems.

Creativity is a mental process that involves the production of new ideas or concepts, or new association among existing ideas/concepts. Creative thinking means an ability to create concepts or ideas considered new and rational. The original idea as a product of creativity is certainly through an adequate prior conceptual understanding. An accurate understanding enables students to compare and analyze any existing concepts to create a new idea that conveys a logical foundation. This supports Jackson's [3] argumentation that based on scientific approach, the product of creative thinking engaging new idea or concept making mostly has originality and conformity. Earlier, Wood and Ashfield [4] reveal that creative learning aims at developing students' creative thinking independently.

Specific measurement technique can identify the level of student's creativity. It is intended to measure the level of creativity performed by students in various steps of science activity, including, observing the problem, generating the hypothesis, testing hypothesis, and presenting results. According to Kampylis \& Valtanen [5], creative activity needs a creative process and creates new and useful creative 
product. In testing students' creativity, the instrument can be developed in the forms of verbal, numerical, and figural tests. The verbal test measures students' ability in expressing ideas and concepts in the forms of written expression. Numerical test is used to find out students' ability in generating ideas based on logical-mathematical thinking. The figural test aims at measuring students' ability in associating ideas by using patterns or images.

Physics education is not apart from experiments as a way of finding evidence of various concepts in physics. Therefore, the laboratory becomes a vital component to facilitate experiments of physics. By engaging in it, students are expected to improve some skills, including observing, measuring, data processing, interpreting, and concluding based on data. Students are also trained to be more creative in conducting every stage of the experiment, in which they are required to discover various concepts on their own. Unfortunately, there are plenty of problems occurred during school laboratory activities. One of the issues is limited space and insufficient utilities to experiment. This problem often becomes the cause of not conducting or eliminating a laboratory activity. As a consequence, students will find troubles to understand materials and concepts of physics, especially the abstract concepts.

Abstract concepts often make teachers to encounter difficulties in delivering course materials. Although, through a real laboratory activity, an abstract concept is difficult to be visualized, which becomes one of the weaknesses of real laboratory activity. Moreover, the real laboratory is considered not effective regarding cost and time management [6] and is considered harmful if no or less comprehensive security protocol is taken. This condition creates a quandary for both classroom and laboratory activities. Less laboratory activity can influence students' understanding of target concepts within a course. Moreover, it may have an impact on the development of students' creativity and accomplishment, of course, goals may go beyond expectation.

The recent development of computer technology provides an opportunity to surmount various problems. Through computer technology, experiment activity in the lab can be designed in a virtual format to overcome weaknesses of real lab activities. The virtual laboratory may assist a course with efficient practices [7] and enable students to conduct various difficult-to-conduct investigations due to some reasons, such as cost, security, or inaccessible activity in real life [8]. Virtual laboratory model may also assist learning by visualizing abstract concepts into more understandable concepts for students [9]. By using a virtual laboratory, students can experience experimental works and find a new experience to improve learning outcomes. It seems to happen because virtual laboratory provides a safe environment that facilitates students in learning theories and concepts, and enables them to run over experiment without risk [10]. The use of virtual lab can assist students with meaningful experiences that deal with concepts, principles, and essential process in learning [11] and, therefore, can raise students' motivation and participation to engage more actively that will improve their learning experiences [12]. Moreover, Cheesman et al. [13] also state that the effectiveness of virtual laboratory can help learners with difficulties in conducting real laboratory tasks.

This study made use of a virtual laboratory in classroom activities. It aims at seeking the effect of using a virtual laboratory towards students' creativity in physics conducted in three schools. Components of creativity being measured were verbal, numerical, and figural in physics education.

\section{METHOD}

The virtual labs were developed by the Macromedia Flash program on some physics concepts. The program developed has been validated by experts, both in the aspect of content and technology that has been used. The virtual laboratory has been used for its effectiveness testing in physics learning in several high schools. This quasiexperimental research employed a pretest-posttest control group design. Research subjects were taken using purposive sampling technique towards 195 students of three schools, i.e., 67 schools A students (34 experimental group and 33 control group), 68 school B students (34 experimental group and 34 control group), and 60 school C students (30 experimental group and 30 control group). Sample school selection was taken based on the distribution of available resources including time, cost and availability of the school become research partners. Choice of more than one school to obtain a comprehensive profile of creativity enhancement on the different characteristic schools.

The experimental groups were given treatment using virtual laboratory, while control groups with conventional learning design. The learning process with a virtual laboratory is carried out for six to eight times, each for 90 minutes. Learning with a virtual laboratory that has been done following four stages, namely introduction, brainstorming, design, and share. After given treatments, this study compares the level of creativity of each school. Data on students' creativity were collected by conducting an open-ended test, in which experts had validated the instrument. The instrument conveyed test on verbal, numerical, and figural components of creativity. Increased level of creativity was determined by average scores (of $\mathrm{N}$ gain). It is expected to avoid failures in interpreting the student's achievement.

\section{RESULT AND DISCUSSION}

Creativity is a complicated process embracing connectivity of people, method, product, and context (of social and culture) that are considered relevant to 
the domain of knowledge [14]. Creative persons are those with a capability to make a precise assessment in the process of flowing facts into ideas, and therefore, to choose and elaborate the ideas [15]. Means of various activities can study creativity and also transformed from skills generated by excellent understanding [16]. Students' creativity can be developed using adequate learning media, in which virtual laboratory is one among others. This study was an attempt to find the improvement of students' creativity in three schools using the virtual laboratory.

Types of creativity measured in this study were verbal, numerical, and figural. The instrument of this study was a test designed as open-ended questions that had been validated by experts. The pretest was given to measure students' creativity before learning took place. The course using virtual laboratory was given to experimental groups, while conventional learning to control groups. At the end of the course, students were given posttest to measure improvement on students' creativity using N-gain test. Figure 1 shows the comparison of average scores of students from experimental groups and control groups of three schools.

Fig. 1 shows the disparity in students' average scores of $\mathrm{N}$-gain in three different schools. Experiment groups of three schools showed higher average scores of $\mathrm{N}$-gain compared to control groups. It showed that there was an improvement in creativity performed by students who engaged in learning using the virtual laboratory. In school A, data showed that students of the experimental group achieved a significantly higher average score than the control group, i.e., each group got 53 (experimental group) and 37 (control group). Level of improvement in school A was found at the moderate level. In school $\mathrm{B}$, the experimental group scored an average score of $\mathrm{N}$-gain of 75 , while the control group was 70 . Even only 5 points, the result showed that the experimental group got higher achievement than the control group. Moreover, both groups in school B recorded high improvement regarding average scores. Furthermore, in school $\mathrm{C}$, the experimental group got an average score of 68 , while the control group got 54 . It showed a significant level of the discrepancy of both groups, in which the experimental group got a higher average score than the control group. However, the level of improvement in school $\mathrm{C}$ was found moderate.

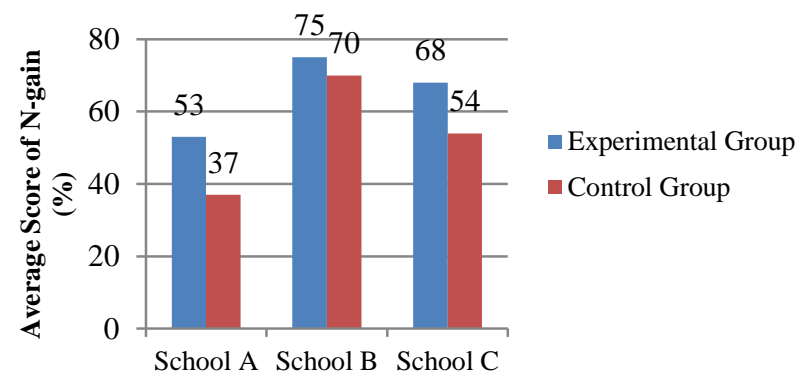

Figure 1 The disparity of score improvement on students' creativity in three schools.

Black \& Bowning [17] reveal that creativity is dealing with discovery, curiosity, imagination, experiment, and exploration. The use of a virtual lab in this study was proven successful in improving students' creativity in all three schools. This finding supports Gunawan et al. [18] who suggests a positive impact of using virtual lab towards students' creativity. In the learning process, students became more creative, especially in two indicators, i.e., fluency and elaboration. The use of virtual lab in natural science classroom can assist efficiency of an experiment [7] and enable students to investigate the phenomenon of elastic through extracting, collecting, and analyze data from experiment sophisticatedly [19]. It also gives particular benefit, i.e., ability to present and teach course material on microscopic, symbolic, and sub-microscopic stages, which encourages students to engage actively in the learning process [10]. A virtual lab enables students to work independently or collaboratively. Another essential thing is allowing students to learn from failure encountered without any real potential damage [20]. Therefore, it makes virtual lab as contributive media to develop students' creativity.

In this study, students' creativity was divided into three types, i.e., verbal, numerical, and figural. Results of these three types of three different schools were compared, as figured in Fig. 2.

Based on Fig. 2, each school scored a different average score of $\mathrm{N}$-gain. It denotes that every school scored different achievements in verbal, and numerical, and figural types of creativity. Hence, every kind of creativity is further elaborated. The first on is verbal creativity. This type of creativity was noted to show the highest improvement in all schools, i.e., 87 by school A, 74 by school B, and 86 by school C. In general, students' improvement on verbal type was categorized as high, more than $70 \%$. This finding showed that students in three schools had excellent performances in solving problems encountered by shaping ideas using verbal communication. 


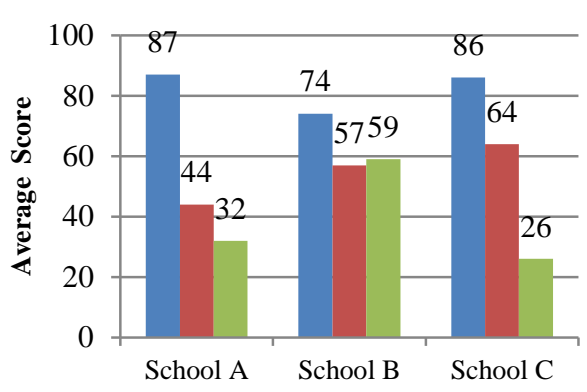

- Verbal

$\square$ Numeric

Figural

Fig. 2. Comparison of scores on verbal, numerical, and figural creativities of experimental groups.

Hence, it can be interpreted that the use of virtual lab can train students to develop their ability to think divergently to combine ideas through words towards certain problem reflected from their fluency, pliancy, originality, and ability to elaborate. This result is in accordance with a study by Gunawan et al. [21] suggesting the use of a virtual lab may give positive impact towards creativity, in which the verbal one increased higher than the figural one. Preckel et al. [22] also state that students' intelligence and creativity have a positive correlation to each other, in which the strongest relationship is on verbal type.

Utilizing virtual lab in learning may encourage students to involve actively in generating deep question towards given problems [6]. During the learning process in the current study, students were required to share opinions and conclusions. At the end of a session, students were asked to explore and discuss various problems encountered during the experiment. All students and teacher conducted this activity as a facilitator. Most of the students welcome and seems to be enthusiastic in utilizing virtual lab in their learning. This finding supports Goodwin et al. [23] who suggests the use of a virtual lab to give significant improvement for students regarding learning sources.

Based on Fig. 2, all schools showed the different average score of $\mathrm{N}$-gain on the numerical type, in which school A of 44, school B of 57, and school C of 64. Averagely, all three schools demonstrated moderate achievements in this type of creativity. This result showed that students of three schools had good ability in solving problems using logical mathematics. It further depicted that the use of virtual lab may improve students' proficiency in organizing information to solve specific issues dealing with numbers, understanding connection/relation of numbers and numerical concepts, and further analyzing it logically. This finding is in line with a study by Oidov et al. [24] that claims the use of a virtual lab may enhance thinking skill and numerical measurement.

Based on Fig. 2, all three schools in this study had made different average scores of $\mathrm{N}$-gain, i.e., school $\mathrm{A}$ of 32, school B of 59, and school C of 26. In this type, students improvement were identified at the moderate level in school $\mathrm{A}$ and $\mathrm{B}$, and low in school $\mathrm{C}$.
Compared to the other two categories, figural type showed the smallest improvement. This finding asserts the finding of a study by Wu et al. [25]. They suggest the lowest level of significance regarding the figural type of creativity. The different result is stated by Garaigordobil [26], which suggests that every treatment given during learning process may give significant positive impact towards improvements on both verbal and figural regarding several indicators, such as fluency, flexibility, and originality. Throughout observation during research, the low level of the figural type of creativity in school $\mathrm{C}$ was possibly triggered by students' unfamiliarity to figural test items. In this sense, it proved that the use of virtual lab in learning activity had not been helpful for students to associate their ideas in the forms of patterns or figures sophisticatedly. This finding is in accordance with a study by Ekasari et al. [27] suggesting the effectiveness of using the virtual lab in direct learning in improving students' verbal type of creativity (the material was about elasticity) but not effective to improve the figural one. This view shows conformity to a claim by Gunawan et al. [28]. In a study developing a virtual lab focusing on the concept of electricity, it was found that the use of this media improved creativity of prospective teacher-students, but the level of figural was found lower than verbal. In addition, Gunawan et al. [29] reported that virtual laboratories in physics learning could improve students' ability to solve problems.

\section{CONCLUSION}

Based on result and analysis of the current study, it can be concluded that the use of virtual lab may improve students' creativity. The improvement was demonstrated higher by the experimental groups compared with the control groups in all three schools selected as research sites. By employing virtual lab, in terms of types of creativity, students showed the highest improvement on verbal one compared to numerical and figural types, in which the lowest one was the figural one. Each school demonstrated the different level of improvement of each type. However, it showed that the use of virtual lab might improve students' creativity.

Call for future research, based on findings; the current study suggests some recommendations necessarily considered in the future study. First, it is necessary to ensure adequate plan and design regarding time allocation for each stage of learning using a virtual lab. Second, the use of virtual lab should be preceded by enough training sessions before conducting the research, especially to students with not sufficient skill in operating basic computer program. Finally, it is necessary to study further with more comprehensive research design on the highest improvement among types of creativity and seek the influence of gender towards each aspect of creativity.

\section{ACKNOWLEDGMENT}

The researcher would like to express gratitude to the Directorate of Research and Community Service, 
Ministry of Research, Technology and Higher Education who has provided the researcher with fund and assistance during the research. The researcher would also like to express gratitude and appreciation to all parties, individuals, and institutions, who have assisted in developing, empirical testing, until publishing this research.

\section{REFERENCES}

[1] G, Gunawan, Keterampilan Berpikir dalam Pembelajaran Sains. Mataram: Arga Puji Press, 2017.

[2] C. Lindstrøm and M. D. Sharma, "Link maps and map meetings: scaffolding student learning," Physical Review Special Topics-Physics Education Research, vol. 5(1), pp. 010102, 2009.

[3] L. A. Jackson, E. A. Witt, A. L. Games, H.E. Fitzgerald, A. von Eye, and Y. Zhao, "Information Technology Use and Creativity: Findings From The Children and Technology Project," Computers In Human Behavior, vol. 28(2), pp. 370376, 2012.

[4] R. Wood and J. Ashfield, "The use of the interactive whiteboard for creative teaching and learning in literacy and mathematics: a case study," British Journal of Educational Technology, vol. 39(1), pp. 84-96, 2008

[5] P. G. Kampylis and J. Valtanen, "Redefining creativity analyzing definitions, collocations, and consequences," Journal of Creative Behavior,vol. 44 (3), pp. 191-214, 2010.

[6] Ye, L., Wong, N. S., and Ho, J. W. Y. "Design, development and evaluation of biochemistry virtual laboratory for blended learning," GSTF Journal on Education (JEd), 2016, 3(2).

[7] A. Salnikov, I. Sliusar, O. Sudakov, O. Savytskyi, and A. Kornelyuk, "Virtual laboratory moldyngrid as a part of scientific infrastructure for biomolecular simulations," International Journal of Computing, vol. 9(4), pp.295-301, 2010.

[8] V. C. Burkett and C. Smith, "Simulated vs. hands-on laboratory position paper," Electronic Journal of Science Education, 2016, 20(9).

[9] G. Gunawan, A. Setiawan, and D. H. Widyantoro, "Mode virtual laboratory fisika modern untuk meningkatkan keterampilan generik sains calon guru," Jurnal Pendidikan dan Pembelajaran (JPP), vol. 20(1), pp.25-32, 2013.

[10] N. R. Herga, B. Čagran, and D. Dinevski, "Virtual laboratory in the role of dynamic visualisation for better understanding of chemistry in primary school," Eurasia Journal of Mathematics, Science \& Technology Education, vol. 12(3), pp. 593-608, 2016.

[11] Z. Tatli and A. Ayas, "Effect of a virtual chemistry laboratory on students' achievement," Educational Technology \& Society, vol. 16(1), pp. 159-170, 2013.

[12] J. Martín-Gutiérrez, C. E. Mora, B. Añorbe-Díaz, and A. González-Marrero, "Virtual technologies trends in education," EURASIA Journal of Mathematics Science and Technology Education, vol. 13(2), pp. 469-486, 2017.

[13] M. J. Cheesman, S. Chen, M. L. Manchadi, T. Jacob, R. F. Minchin, and P. A. Tregloan, "Implementation of a virtual laboratory practical class (vlpc) module in pharmacology education," Pharmacognosy Communications, 2014, 4(1): 2.

[14] E. Zimmerman, "Creativity and art education: a personal journey in four acts," Art Education, vol. 63(5), pp. 84-92, 2010
[15] K. J. Rawat, W. Qazi, and S. Hamid, "Creativity and education," Academic Research International, vol. 2(2), p. 264, 2012,.

[16] Aktamis, Hilal, and O. Ergin. "The effect of scientific process skills education on students' scientific creativity, science attitudes, and academic achievements," Asia-Pacific Forum on Science Learning and Teaching. Vol. 9. No. 1. Hong Kong Institute of Education. 10 Lo Ping Road, Tai Po, New Territories, Hong Kong, 2008.

[17] J. Black and K. Browning, "Creativity in digital art education teaching practices," Art Education, vol. 64(5), pp. 19-34, 2011.

[18] G. Gunawan, A. Harjono, H. Sahidu, and N. Nisrina, "Improving students' creativity using cooperative learning with virtual media on static fluid concept," Journal of Physics: Conference Series, vol. 1006 (1) p. 012016, 2018, April.

[19] D. Amendola and C. Miceli, "Online physics laboratory for university courses" Journal of e-Learning and Knowledge Society, 2016, 12(3).

[20] X. Chen, G. Song, and Y. Zhang, "Virtual and remote laboratory development: a review," In Earth and Space 2010 Engineering, Science, Construction, and Operations in Challenging Environments, 2010, pp. 3843-3852.

[21] G. Gunawan, H. Sahidu, A. Harjono, and N. M. Y. Suranti, "The effect of project based learning with virtual media assistance on student's creativity in physics," Cakrawala Pendidikan, vol. 36(2), pp. 167-179, 2017c.

[22] F. Preckel, H. Holling, and M. Wiese, "Relationship of intelligence and creativity in gifted and non-gifted students: An investigation of threshold theory," Personality and Individual Differences, vol. 40(1): pp. 159-170, 2006.

[23] G. C. Goodwin, A. M. Medioli, W. Sher, L. B. Vlacic, and J. S. Welsh, "Emulation-based virtual laboratories: a low-cost alternative to physical experiments in control engineering education," IEEE Transactions on Education, vol. 54(1), pp. 48-55, 2011.

[24] L. Oidov, U. Tortogtokh, and E. Purevdagva, "Virtual laboratory for physics teaching," In International Conference on Management and Education Innovatio, IPEDR, vol. 37, pp. 319-323, 2012.

[25] C. H. Wu, Y. Cheng, H. Ip, and C. McBride-Chang, "Age differences in creativity: task structure and knowledge base," Creativity Research Journal, vol. 17(4), pp321-326, 2005.

[26] M. Garaigordobil, "Intervention in creativity with children aged 10 and 11 years: Impact of a play program on verbal and graphic-figural creativity," Creativity Research Journal, vol 18(3), pp329-345, 2006.

[27] R. R. Ekasari, G. Gunawan, and H. Sahidu, "Pengaruh Model pembelajaran langsung berbantuan media laboratorium terhadap kreatifitas fisika siswa SMA." Jurnal Pendidikan Fisika dan Teknologi, vol. 2(3), pp. 106-110, 2016.

[28] G. Gunawan, A. Harjono, H. Sahidu, and L. Herayanti, "Virtual laboratory of electricity concept to improve prospective physics teachers' creativity," Jurnal Pendidikan Fisika Indonesia, vol 13(2), pp102-111, 2017a.

[29] G. Gunawan, A. Harjono, H. Sahidu, and L. Herayanti, "Virtual laboratory to improve students' problem-solving skills on electricity concept," Jurnal Pendidikan IPA Indonesia, vol. 6(2), pp 257-264, $2017 \mathrm{~b}$. 